\title{
Removal of Humic Acid from Natural Water by $\mathrm{ZVI} / \mathrm{H}_{2} \mathrm{O}_{2}$ Process
}

\author{
NO Santos ${ }^{1}$, JC Spadotto ${ }^{1}$, MG Burke², IG Solórzano ${ }^{1}$, LC Campos ${ }^{3}$ and LAC Teixeira ${ }^{1}$ \\ 1. Department of Chemical and Materials Engineering, PUC-Rio, Rio de Janeiro, Brazil. \\ 2. Materials Performance Centre, University of Manchester, Manchester, UK. \\ 3. Department of Civil, Environmental and Geomatic Engineering, UCL, London, UK. \\ * Corresponding author: naiara.pucrio@gmail.com
}

Humic acid (HA), a representative fraction of the natural organic matter derived from vegetation and commonly present in natural waters, can contribute to the formation of disinfection by-products when reacting with chlorine during potable water production. These by-products may cause increased risk of cancer, especially in the bladder, and adverse reproductive outcomes [1]. Therefore, identification and removal of organic matter before the chlorination step is required to avoid or minimize the risk of formation of these by-products.

The advanced oxidation process Zero Valent Iron/Hydrogen Peroxide $\left(\mathrm{ZVI} / \mathrm{H}_{2} \mathrm{O}_{2}\right)$ has already been investigated by the present authors [2]. However, the water matrix studied was produced in the laboratory with PA reagent HA, which, according to the recent studies $[3,4]$ may not be a representative matrix for aquatic environments, and may not properly demonstrate the feasibility of applying in full-scale the proposed removal process. The present study has investigated the HA removal efficiency and the oxidation mechanism of the ZVI in natural water collected from Regent's Park (London, UK - 51 ${ }^{\circ} 31^{\prime} 32^{\prime} \mathrm{N} 0{ }^{\circ} 09^{\prime} 28 \mathrm{~W}$ ), which contained an average dissolved organic carbon (DOC) $5.3 \pm 2.2 \mathrm{mg} . \mathrm{L}^{-1}$ and turbidity $1.2 \pm 0.6 \mathrm{NTU}$. Experiments were performed with ZVI in the metallic form of iron "cuts" (small nails) (total surface area $\left.2.56 \mathrm{~cm}^{2}\right)$ and $\mathrm{H}_{2} \mathrm{O}_{2}(50 \% \mathrm{w} / \mathrm{w}$ ) at initial pH 4.5. Humic acid degradation was evaluated in terms of DOC and absorption at $\mathrm{UV}_{254}$. The microstructure of the oxidized ZVI was evaluated using a Zeiss Merlin field emission gun (FEG) scanning electron microscope (SEM), and a Zeiss Sigma VP FEG-SEM. Low voltage $(1.5 \mathrm{kV})$ energy dispersive x-ray (EDX) spectrum image datasets were obtained using an Oxford Instruments X-Max Extreme Si Drift Detector (SDD) and AZTEC analysis system to qualitatively assess the elemental distribution in the near-surface $(\sim 20-30 \mathrm{~nm})$ region of the oxidized samples.

The secondary electron (SE) SEM image in Figure 1a shows the ZVI surface in the as-received condition (before the $\mathrm{ZVI} / \mathrm{H}_{2} \mathrm{O}_{2}$ reaction). Figure $1 \mathrm{~b}$ shows the $\mathrm{ZVI}$ surface after the $\mathrm{ZVI} / \mathrm{H}_{2} \mathrm{O}_{2}$ reaction. This $\mathrm{SE}$ image revealed the presence of oxides that formed on the metallic Fe surface. These oxides confirm that oxidation of ZVI by the $\mathrm{H}_{2} \mathrm{O}_{2}$ had occurred in the solution as described by Eq. (1). As expected in this oxidative process, metallic Fe is oxidized by $\mathrm{H}_{2} \mathrm{O}_{2}$ to form ferrous iron, releasing ions into solution which subsequently react with $\mathrm{H}_{2} \mathrm{O}_{2}$ to produce a highly reactive radical $(\mathrm{OH})$ for the degradation of the organic matter (Eqs. $(1-3)$ ). Thus, a significant difference in oxidation is evident from the different oxide morphologies between Figures 1a (as-received native oxide on Fe prior to exposure) and $1 \mathrm{~b}$ (after the $\mathrm{ZVI} / \mathrm{H}_{2} \mathrm{O}_{2}$ process) confirming the oxidation mechanistic step of the $\mathrm{ZVI} / \mathrm{H}_{2} \mathrm{O}_{2}$ process. Figures $2 \mathrm{a}$ and $2 \mathrm{~b}$ show the formation of oxides with heterogeneous morphologies on the ZVI surface after the $\mathrm{ZVI} / \mathrm{H}_{2} \mathrm{O}_{2}$ process. In Figure $3 \mathrm{a}$ the coexistence of two different morphologies can be observed in the same region. These different morphologies may be due to $\mathrm{pH}$ variation during the reaction, producing a variety of stable iron oxides. The LV SEM-EDX elemental maps confirming the presence of oxygen in the near-surface region of the exposed Fe specimens are presented in Figures $3 \mathrm{~b}$ and $3 \mathrm{c}$.

$$
\begin{aligned}
& \mathrm{Fe}^{0}+\mathrm{H}_{2} \mathrm{O}_{2}+2 \mathrm{H}^{+} \rightarrow \mathrm{Fe}^{2+}+2 \mathrm{H}_{2} \mathrm{O} \\
& \mathrm{Fe}^{2+}+\mathrm{H}_{2} \mathrm{O}_{2} \rightarrow \mathrm{Fe}^{3+}+\cdot \mathrm{OH}+\mathrm{OH}^{-} \\
& \cdot \mathrm{OH}+\text { organics } \rightarrow \text { oxidized products }
\end{aligned}
$$

As result of the $\mathrm{ZVI} / \mathrm{H}_{2} \mathrm{O}_{2}$ process, treated water showed $82 \% \mathrm{HA}$ removal at $\mathrm{UV}_{254}, 51 \%$ dissolved organic carbon (DOC) mineralization, and $0.82 \pm 0.02 \mathrm{mg} . \mathrm{L}^{-1}$ of $\mathrm{Fe}^{2+}$ formation in $75 \mathrm{~min}$ of reaction. From these results, 
it can be concluded that the $\mathrm{Fe}^{0}$ "nail" samples were severely corroded by the $\mathrm{H}_{2} \mathrm{O}_{2}$ oxidizer, leading to the degradation of the undesirable organic matter through the treatment with the $\mathrm{ZVI} / \mathrm{H}_{2} \mathrm{O}_{2}$ process [5].

References:

[1] Karanfil et al., Disinfection By-Products in Drinking Water (2008), p. 2.

[2] Santos et al., Microscopy \& Microanalysis 24 (2018), p. 696.

[3] Rodriguez et al., Science of the Total Environment 476-477 (2014), p. 718.

[4] Artifon et al., Science of the Total Environment 649 (2019), p. 1620.

[5] The authors are grateful to the Brazilian Research Funding Agencies- CNPq and FAPERJ. The assistance of L.Volpe of the Materials Performance Centre and the support of Peroxidos do Brasil Ltda (Solvay Group) is gratefully acknowledged.
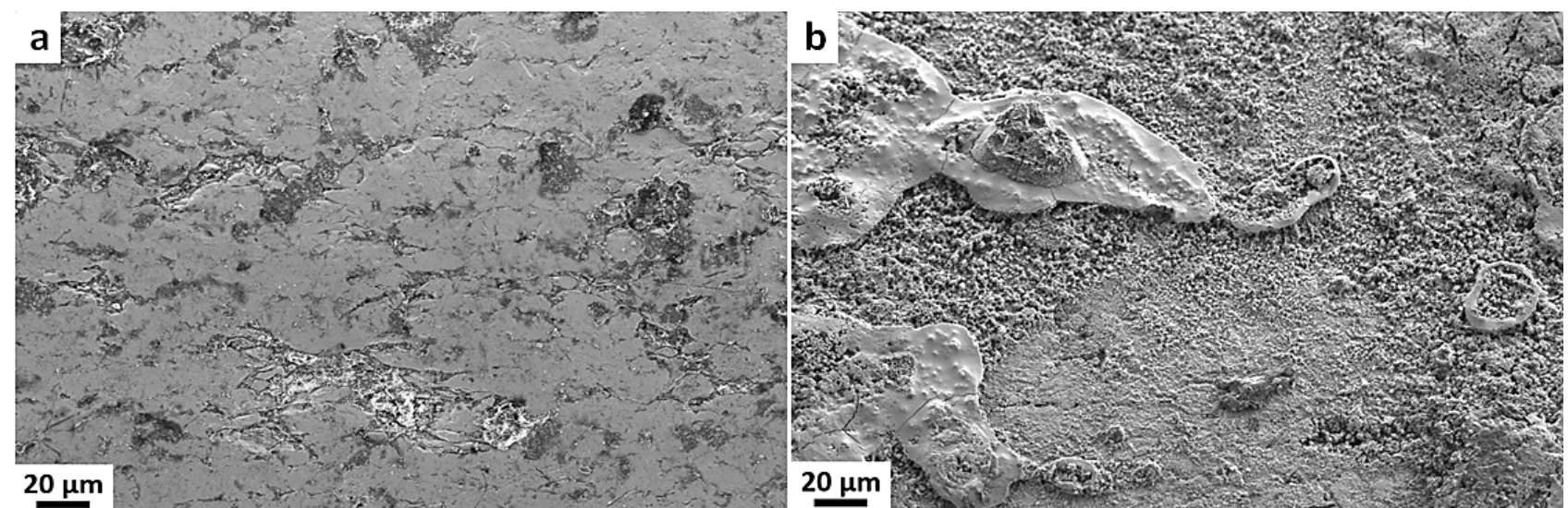

Figure 1. SE images of iron cuts surface. (a) as-received condition and (b) post-ZVI/ $\mathrm{H}_{2} \mathrm{O}_{2}$ in 75 minutes of reaction.
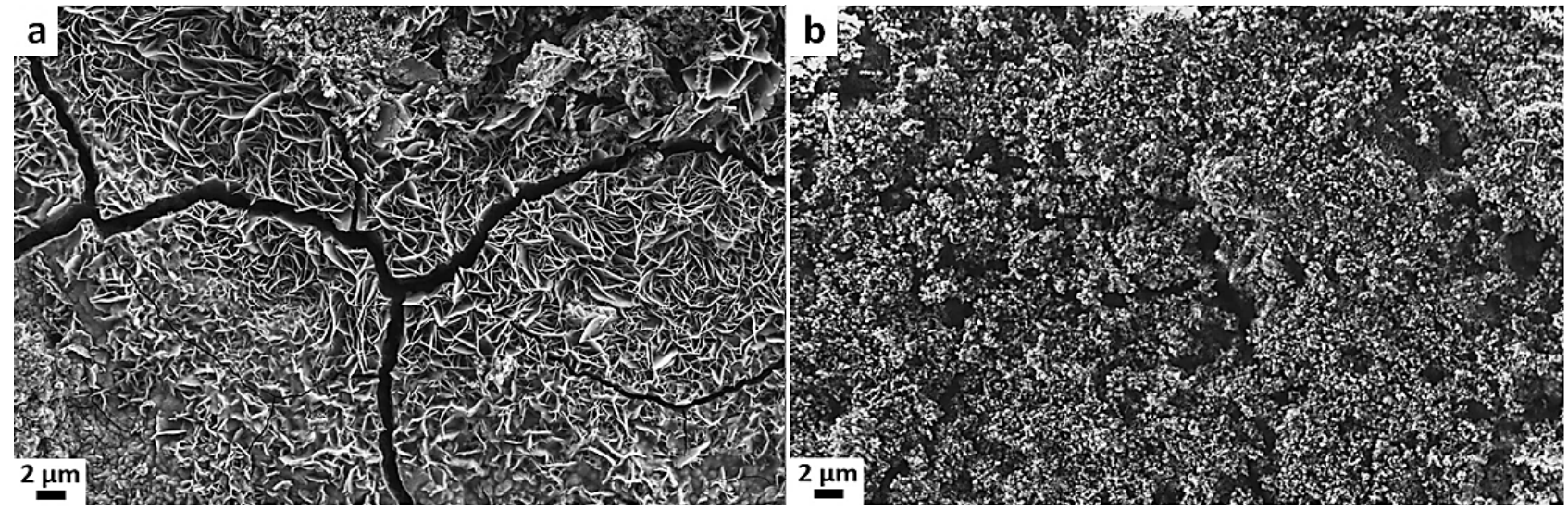

Figure 2. SE images of oxides on the Fe sample surface post- $\mathrm{ZVI} / \mathrm{H}_{2} \mathrm{O}_{2}$ in 75 minutes of reaction.
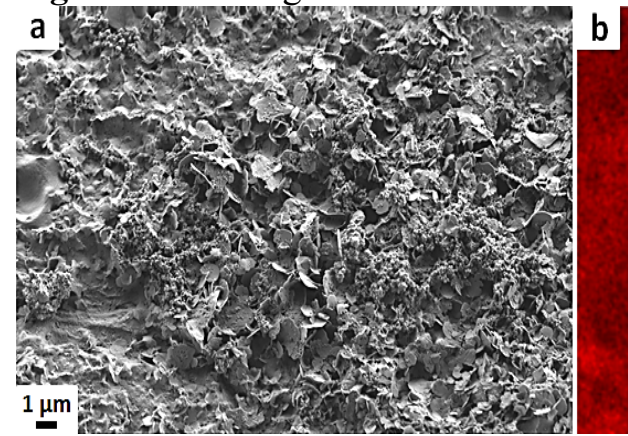

Figure 3. (a) SE image of oxidized Fe surface post- $\mathrm{ZVI} / \mathrm{H}_{2} \mathrm{O}_{2}$ process; (b) complementary LV EDX maps of $\mathrm{Fe}$ and O. 